\title{
How is the Triple Helix Model Being Understood in Latin America? The Case of Mexico
}

\author{
Judith Zubieta and Jaime Jiménez
}

It is generally accepted that Mexican science entered its modern stage in the early 1970's, with the inception of the National Council of Science and Technology (CONACYT). One of CONACYT's major objectives was to plan and promote Mexican science and technology (S\&T). CONACYT was created to develop science as an engine for national development. Its mission was to establish support projects related to national problems. At the time, Mexican science was devoted to the general enhancement of universal knowledge. Thus, CONACYT's initial statement scared pure scientists since they believed government research support would no longer be directed at their own projects. Science and technology policy, however, was not properly implemented since only the most prestigious scientists, devoted to basic scientific research, constituted CONACYT's scientific committees charged with evaluating research grant proposals. This struggle has continued to this day even though some changes have taken place. Among the most important changes is a gradual trend towards a more equitable budget distribution between basic and applied scientific projects.

During the 1970's, medium-sized industry entrepreneurs and academics foresaw the convenience of helping industry, located in the provinces, develop through the creation of S\&T research units. Efforts were made to get the funds needed for that purpose. Some of these initiatives found echoes within local governments and thus received partial subsidies. In addition, these entrepreneurs had to look for scientific knowledge to carry out the projects they wanted to be involved with, which was to be found in academic institutions. Unfortunately, the pace at which some research and development (R\&D) centres were created during the 1970's, was not observed in the 1980's or 1990's, thus leaving those centres already operating, isolated in terms of their possible interaction with other similar institutions.

It was not until 1992 that CONACYT implemented a policy through which an 
R\&D "system" was established with 26 public institutions, most of which were created during the 1970's. Non-interrelated parts, however, constituted the "system." Even though some of the institutions were aware of the existence of others, they did not interact. The systemic nature of this group eventually emerged, enhancing their potentialities and thus capitalising the benefits of interdisciplinary and more ambitious programs and projects. The so-called SEP-CONACYT system currently includes a total of 27 institutions, which may be grouped into three subsystems: scientific research, research in social sciences, and technology. ${ }^{1}$ SEP is the Ministry of Public Education, the ministry charged with the funding and supervision of CONACYT's performance.

This paper concentrates on the transformation processes the technology subsystem has gone through in order to achieve the goal of linking together knowledge generated by universities and industrial applications, under the sponsorship and normative framework of the federal government.

\section{The SEP-CONACYT Technology Subsystem}

The SEP-CONACYT technology subsys$t^{2}{ }^{2}$ is integrated by seven institutions (see Table 1), in a wide range of areas of expertise, both in the scientific and tech-

Table 1.Description of the SEP-CONACYTTechnology Subsystem

\begin{tabular}{|c|c|}
\hline $\begin{array}{l}\text { CIQA } \\
(1974)\end{array}$ & $\begin{array}{l}\text { Synthesis of new materials with specific properties. } \\
\text { Synthesis of special additives for polymers; polymer biosynthesis. } \\
\text { Photobiodegradable polymers. }\end{array}$ \\
\hline $\begin{array}{l}\text { CIATEC } \\
(1975)\end{array}$ & $\begin{array}{l}\text { Manufacturing processes for the leather and shoe industry as } \\
\text { well as other related areas. } \\
\text { Design and optimisation of industrial processes. Training. } \\
\text { Product design and development. Metrology. }\end{array}$ \\
\hline $\begin{array}{l}\text { COMIMSA } \\
(1975)\end{array}$ & $\begin{array}{l}\text { Technological Services } \\
\text { Metallurgy with emphasis on steel. } \\
\text { Diagnosis and repair of turbomachinery. } \\
\text { Environmental engineering and special studies. }\end{array}$ \\
\hline $\begin{array}{l}\text { CIATEJ } \\
(1976)\end{array}$ & $\begin{array}{l}\text { Fermentation processes in agroindustry for the production of } \\
\text { food, beverages, and additives. } \\
\text { Treatment and disposal of food related effluents. } \\
\text { Massive food production; genetic improvement. }\end{array}$ \\
\hline $\begin{array}{l}\text { CIATEQ } \\
(1978)\end{array}$ & $\begin{array}{l}\text { Machinery and automation. Mechanical Construction. } \\
\text { Systems engineering, instrumentation, and control. } \\
\text { Mechanical transmissions. Agroindustrial machinery. }\end{array}$ \\
\hline $\begin{array}{l}\text { CIDESI } \\
(1984)\end{array}$ & $\begin{array}{l}\text { Metrology and Training. Mechanics and mechatronics. } \\
\text { Material recycling. Lab testing. } \\
\text { New materials (metal and non-metal). }\end{array}$ \\
\hline $\begin{array}{l}\text { CIDETEQ } \\
(1991)\end{array}$ & $\begin{array}{l}\text { Electrochemical processes. } \\
\text { Water treatment. Surfaces treatment. }\end{array}$ \\
\hline
\end{tabular}


nological areas. These areas of expertise, however, have not been determined according to a plan or drawn out of a policy strategy. Instead, they have arisen from the particular interests of specific industries or individuals.

\section{Description and Geographic Location}

Closely linked to intense industrial activities taking place in the country's north-eastern region, the Centre for Research on Applied Chemistry (CIQA), located in Saltillo, is the eldest institution in the subsystem. Created in 1974, it is primarily devoted to research on polymers. Chronologically, the Centre for Research and Technology Consulting on Leather and Shoe (CIATEC) was created a year later and its aim is to serve the leather and shoe industry. According to its local origin and specific objectives, it is conveniently located in León, Guanajuato, one of the most important Mexican states in the production of leather-related products.

The Mexican Corporation on Materials Research (COMIMSA) was the third centre to be created and is currently the sole institution portraying its name in a different legal form. Indeed, it is the only centre from the whole SEP-CONACYT system that was legally established as an enterprise and its activities are concerned with various metallurgy-related areas. Geographically, it is located in the city of Saltillo, just like CIQA.

The Centre of Research, Technology and Design Consulting in the state of Jalisco (CIATEJ) was originally created to solve problems for the jewellery industry, but its main interests have long been redirected towards food related proc- esses, and lately focused on the tequila industry. ${ }^{3}$ Like CIATEC this R\&D institution is strategically located according to the particular industrial sector it serves, in the city of Guadalajara.

Three R\&D centres are located in Querétaro, north of Mexico City, a state that has become a prosperous agricultural and industrial region, in the middle of the Mexican territory. The Centre for Research and Technical Assistance (CIATEQ), the Centre of Industrial and Development Engineering (CIDESI), and the Centre for Electrochemical Research and Technology Development (CIDETEQ) share some common interests. The first two present some similarities in their research topics since their operations are concerned with mechanical and systems engineering, thus overlapping some of their capacities and strengths. CIDETEQ, however, has focused on electrochemical processes.

In the last two decades, some authors (see Jimenez et al., 1986; 1991) have shown that S\&T resource allocation has long favoured large metropolitan areas, which in turn host highly prestigious universities. Mexico is not an exception to this pattern, which has challenged other academic institutions located in peripheral provinces. Indeed, the centre-periphery dilemma has deepened already existing differences and widened development inequalities among regions. Contrary to this tradition, the SEPCONACYT centres are scattered through out the territory, each of them becoming a potential regional development pole.

The technology subsystem has not faced the problems arising from highly concentrated areas where the supply of similar services is considerable even 
though there might be a larger number of clients. Other academic institutions including SEP-CONACYT scientific and social sciences subsystems - are geographically concentrated due to their own research disciplines, which are closely related to new opportunities and access to special funds, equipment, facilities, and graduate students (Jiménez et al., 1991). Factors influencing location of $R \& D$ have also been widely studied in Canada (Anderson, 1998).

These centres were created in a reactive fashion as an answer to isolated individual initiatives or requests. Some of these initiatives originated among people in different industrial sectors, recognising the potential outcomes of S\&T projects they could benefit from; others realised the need to establish interactive links with academic institutions which at that time were not to be found in their surrounding areas. ${ }^{4}$ In other cases, Mexican scientists born in the provinces, doing research in the metropolitan area of Mexico City, had expressed intentions of moving back to their smaller communities, particularly those with a solid academic reputation. These researchers established contacts with local academic institutions and industry, trying to develop conditions to guarantee local or regional support and funding for their plans and projects.

Numerous efforts were carried out during those years. Some of them did not succeed due to a lack of compliance with local and regional needs or interests, while others faced the absence of support from funding agencies, to subsidise their initial operations. While all of them faced many obstacles and uncertainties, a few succeeded and eventually grew to well-established R\&D institutions. Un- fortunately, little is known about those which ended before an agreement could be set, either because local or federal governments were not interested or because they could not find other agencies to support their initiatives.

\section{Institutional Size and Complexity}

The overall size of the whole technology subsystem is relatively large, compared to the rest of the SEP-CONACYT system. Data for 1998 show there were 1757 employees officially working and hired to perform various tasks. The average size is almost 251 per centre. Real sizes, however, may vary from one centre to another. For instance, CIDETEQ has 60 employees while COMIMSA, by far the largest one reports 850 persons, including non-permanent employees.

Mexican public academic institutions have in general suffered from heavy pyramidal administrative bodies reflected in most government structures where bureaucracy permeates almost every layer of an organisation. Contrary to this tradition, centres in the technology subsystem have managed to stay slim partly because of their average size, short lifespan and most surprisingly, due to current federal regulations.

A fundamental part of the human resources working in these centres are the scientific and technological personnel (S\&TP), which usually include people with higher academic degrees and/or experience in their areas of expertise. Data for 1998 show a total of 1,472 scientific and technology personnel (see Table 2). Whether the proportions of this S\&TP with respect to the full size of each centre are similar, or if they vary, it is within a range, which could be regarded 
as understandable given their particular disciplines and activities. In fact, Table 2 shows CIDESI with the lowest proportion of S\&TP, while COMIMSA and CIATEQ are the only two institutions with the largest number of scientists and engineers. Despite this, according to some data and facts, which will be discussed in the forthcoming paragraphs, COMIMSA has not hired faculty or academic personnel with higher degrees; rather its technicians have been employed as S\&TP due to their experience.

In general and regardless of size, these centres show an adequate S\&TP ratio, which may be interpreted as a result of a good organisational design as much as appropriate administrative structures. The exceptions are CIDESI, CIDETEQ and CIQA, which fall below 75\%, a figure that has been regarded as the lowest desired proportion. These centres may be considered unique in so far as administrative and support personnel are no larger than those in charge of the substantial operations, which helps to control the impact that administrative costs have on the overall annual institutional expenditures. Those centres which did not comply with the suggested S\&TP ratio must tighten their hiring policies in order to become administratively effective, and concentrate in the design of more aggressive procedures to recruit S\&TP members devoted to the core activities, which will lead them to attain their goals more effectively.

\section{Core Human Capital (S\&TP)}

As opposed to most universities or academic institutions, the centres do not include a high percentage of researchers with graduate degrees - the core human capital in S\&T. Engineers, as opposed to scientists, have proven to be more adequate and sought after given the type of projects being carried out and in the attainment of institutional objectives. The term by which these technicians are usually referred to is "technological personnel" and it is widely accepted that their areas of expertise and training are not in accordance with graduate degrees. Indeed, the nature of problems this type of personnel face in

Table 2. Human Resources, 1998

\begin{tabular}{|lrcc|}
\hline Centre & S\&TP & $\begin{array}{c}\text { Total } \\
\text { Personnel }\end{array}$ & $\%$ \\
CIQA & 120 & 166 & $72 \%$ \\
CIATEC & 81 & 103 & $79 \%$ \\
COMIMSA & 778 & 850 & $92 \%$ \\
CIATEJ & 94 & 115 & $82 \%$ \\
CIATEQ & 238 & 260 & $92 \%$ \\
CIDESI & 117 & 203 & $58 \%$ \\
CIDETEQ & 44 & 60 & $73 \%$ \\
& & & \\
Total & 1352 & 1591 & $85 \%$ \\
\end{tabular}

S\&TP: scientific and technical personnel. 
Table 3. Academic Indicators, 1998

\begin{tabular}{|lcccc|}
\hline Centre & $\begin{array}{c}\text { S\&TP with } \\
\text { Master's }\end{array}$ & $\begin{array}{c}\text { S\&TP } \\
\text { with PhD }\end{array}$ & $\begin{array}{c}\text { Researchers } \\
\text { in S.N.I }\end{array}$ & $\begin{array}{c}\text { Total No. of } \\
\text { Researchers }\end{array}$ \\
CIQA & 44 & 20 & 21 & 44 \\
CIATEC & 11 & 2 & 1 & 59 \\
COMIMSA & 81 & 6 & 0 & 48 \\
CIATEJ & 24 & 13 & 11 & 57 \\
CIATEQ & 28 & 8 & 3 & 120 \\
CIDESI & 10 & 0 & 0 & 41 \\
CIDETEQ & 13 & 7 & 5 & 20 \\
TOTAL & 167 & 36 & 20 & 345 \\
\hline
\end{tabular}

SNI: National System of Researchers.

industry does not require highly sophisticated scientific knowledge, since in most cases they are not in the high-tech domain.

Table 3 shows the distribution of human resources in terms of their academic attributes. It is worth mentioning that S\&TP is made up of researchers and technicians; the former are responsible for projects and services provided, while the latter are expected to technically assist researchers.

The highest number of researchers is found in CIATEC, with 73\%, CIATEJ with $61 \%$ and CIATEQ with $50 \%$ of its S\&TP; all others fail to reach $50 \%$, with COMIMSA with the lowest figure of $6 \%$. The main concern of all technology centres is to guarantee that services offered comply with international standards. The emphasis on satisfying industry needs and the quality of the services provided, rather than on publishing scientific papers is also revealed in the low participation of researchers in the National Sys- tem of Researchers (SNI). Created in 1984, SNI operates as a government agency closely related to CONACYT, and in charge of fostering national S\&T through incentives to individuals with high academic performance. Table 3 indicates that an average of only $11 \%$ of researchers within the technology subsystem participate in SNI while only two centres show two-digit figures with regard to this participation.

Graduate degrees are required in order to become a member of SNI. It is generally accepted that a higher academic degree is necessary for developing ambitious and innovative S\&T projects. Indeed, those two centres with the highest SNI participation are the ones with higher percentages of researchers with graduate degrees. Unfortunately, should the opportunity arise to become involved in projects demanding more advanced technology and knowledge, the data also reveals that these centres would not be able to maintain their cur- 
rent competitive status, since more than half of their S\&TP do not possess university degrees at all.

\section{Performance Assessment}

The overall institutional performance of this subsystem is mixed. Some centres have become instrumental in the modernisation of industries; others have played a minor role in the insertion of industries into the mainstream economy. As for teaching, there is room for improvement in all of them, not only in terms of the graduate programs being offered but also in terms of special training for personnel from industry. A third dimension to beassessed is the performance of scientific research and technology development, in which only three centres qualify: CIQA, CIDETEQ and CIATEJ.

\section{Institutional Linkages and Industry Interactions}

It should be noted that all links established by these centres have to be understood in a wider context of articulation with other entities - including within the SEP-CONACYT system. As such, an indicator traditionally used to measure the level of activity is expressed in terms of the economic resources they generate. A more refined indicator is the ratio of contract income to total budget. ${ }^{5}$

These simple indicators allow the assessment of the profitability of links between the SEP-CONACYT technology subsystem and industry. They also indicate the likelihood of economic self-sufficiency, an issue that has recently raised concerns, especially for those whose budgets are still highly dependent on federal subsidies. It has to be recognised that economic self-sufficiency offers a challenge in itself; indeed, these centres should seek for projects where they may offer competitive advantages, as well as more aggressive marketing strategies to reach out to new clients in the industrial sector, where they will be more likely to obtain a higher economic profit. Table 4 gives us a clear image of the economic profitability of the centres. It could be inferred that the longer time a centre has been operating, the better its standing and competitiveness, however, the fig-

Table 4. Distribution of Annual Budgets, 1998

\begin{tabular}{|lcc|}
\hline Centre & Own Resources & Federal Resources \\
& & \\
CIQA (1974) & $12 \%$ & $88 \%$ \\
CIATEC (1975) & $21 \%$ & $79 \%$ \\
COMIMSA (1975) & $99 \%$ & $1 \%$ \\
CIATEJ (1976) & $18 \%$ & $82 \%$ \\
CIATEQ (1978) & $39 \%$ & $61 \%$ \\
CIDESI (1984) & $14 \%$ & $86 \%$ \\
CIDETEQ (1991) & $14 \%$ & $86 \%$ \\
\hline
\end{tabular}


ures show that there is no direct relation between age and profitability.

For instance, CIQA has been operating for almost 25 years in the same field of research, but has not yet been able to increase its self-generated resources beyond $15 \%$. The same holds for other centres like CIATEJ and CIDESI, which still lie below the $15 \%$ barrier, and CIDETEQ, the youngest institution in the subsystem, whose size is half the others but whose profitability is yet to be seen.

With regard to total expenditures for 1998 , an average of only $31 \%$ was generated by the subsystem itself through contract projects and services, including COMIMSA, the single centre contributing the largest amount of self-generated income. However, if this centre were left out of the annual figures, the average would drop to a $20 \%$ proportion, which by no means should be considered low, but which evidently shows a strong dependence on the federal budget. As we pointed out earlier, COMIMSA was created as an enterprise, thus its concept was different from other R\&D centres. In doing so, it has had the leadership needed to design and adopt successful business strategies. It has started to develop links in the form of "joint ventures" with other centres within the SEPCONACYT system. In particular, those with academic capabilities and abilities to engage in $R \& D$ projects and can be developed under COMIMSA's supervision.

\section{Provision of Services}

An indicator of the quality in the assessment of services rendered by these seven centres focuses on repetitiveness. If a first-time client goes for a second service, it indicates a certain level of satisfaction, which in turn will be translated into more stable client-provider relationships.

In $1998,83 \%$ of the services provided were contracted by first-time enterprises while only $17 \%$ by repeating companies, which had already contracted one service from that centre at least once before. Even though this figure is rather low, by

Table 5. Services Provided by Centre, 1998

\begin{tabular}{|lcc|}
\hline Centre & $\begin{array}{c}\text { Services rendered to } \\
\text { repeating clients }\end{array}$ & $\begin{array}{c}\text { Services rendered to } \\
\text { first-time clients }\end{array}$ \\
CIQA & $38 \%$ & $62 \%$ \\
CIATEC & $86 \%$ & $14 \%$ \\
COMIMSA & $\mathrm{n} . \mathrm{a}$. & $\mathrm{n} . \mathrm{a}$ \\
CIATEJ & $3 \%$ & $97 \%$ \\
CIATEQ & $64 \%$ & $36 \%$ \\
CIDESI & $47 \%$ & $53 \%$ \\
CIDETEQ & $85 \%$ & $15 \%$ \\
Average & $47 \%$ & $36 \%$ \\
\hline
\end{tabular}


no means should it be interpreted as a lack of quality in the services offered; rather, it makes explicit the challenges they are facing in developing long-term relationships with their clients. Appropriate marketing strategies will have to be designed as well as comprehensive contract projects for potential markets already detected. Table 5 shows CIDESI and CIQA with an equitable proportion of both types of clients, while CIATEQ and CIDETEQ have already built up a longer relationship with previously served clients. The latter should translate into feasible opportunities to develop long-term projects in the near future.

A different perspective arises when analysing self-generated income and the total number of services. The latter by itself could lead to some misunderstanding of the concept of services rendered, since it is not proportional to income. Table 6 gives an idea of which services are proving to be more profitable, in terms of the money they bring to the

Table 6. Profitability of Services, 1998

\begin{tabular}{|lrr|}
\hline Centre & $\begin{array}{c}\text { Total } \\
\text { Services }\end{array}$ & $\begin{array}{c}\text { Avg. Income } \\
\text { per Service }\end{array}$ \\
CIQA & 546 & 10 \\
CIATEC & 6864 & 1 \\
COMIMSA & 42900 & 14 \\
CIATEJ & 2709 & 3 \\
CIATEQ & 98 & 311 \\
CIDESI & 7449 & 1 \\
CIDETEQ & 671 & 6 \\
& & \\
\hline
\end{tabular}

(In thousands of Mexican pesos.

Ca. 10 Mexican pesos per one U.S. dollar) corresponding centre. Thus, CIATEQ is an example of profitable business, even though its number of services is the smallest in the subsystem.

Another useful indicator, which may lead to the design of innovative alternatives, deals with the ratio of total income generated per client or contract. Table 7 shows the 1998 share figures for all seven centres. It is clear that in 1998 CIATEC was the single centre to invoice $33 \%$ from the total number of clients in the whole subsystem, while the income generated by its clients accounted for only $1.1 \%$ of the total figure of self-generated resources.

The opposite is observed in COMIMSA, the single centre absorbing 9\% of the total number of clients while obtaining from them resources enough to cover $95 \%$ of their own expenditures, equivalent to $90.7 \%$ from all subsystem's self-generated income. While this performance may seem highly desirable for any institution, it raises the question of economic dependability on a few clients.

Table 7. Income Generated by Services Provided, 1998

\begin{tabular}{|lrc|}
\hline Centre & Clients & $\begin{array}{c}\text { Self-generated } \\
\text { Income }\end{array}$ \\
CIQA & $7 \%$ & $0.8 \%$ \\
CIATEC & $33 \%$ & $1.1 \%$ \\
COMIMSA & $9 \%$ & $90.7 \%$ \\
CIATEJ & $14 \%$ & $1.2 \%$ \\
CIATEQ & $4 \%$ & $4.5 \%$ \\
CIDESI & $29 \%$ & $1.1 \%$ \\
CIDETEQ & $4 \%$ & $0.6 \%$ \\
& & \\
\hline
\end{tabular}


Table 8 shows institutional marketing performance in terms of projects being commercialised, in comparison with the total number of projects developed during 1998. Even though it is clear that most of these projects were actually sold to industry, there are three centres whose percentages were much lower: CIQA, CIATEJ, and CIDETEQ.

Once it has been shown that most centres in the technology subsystem are indeed capable of marketing their own products, they should assess the convenience of adopting either one of two strategic alternatives, or both. The first one is to set tighter links with universities and/or other R\&D centres in order to develop projects involving more sophisticated technologies. Second, they should develop links with industries and the private sector in general, to improve their marketing strategies. Obviously, the latter involves the risk of becoming fo-

Table 8. Projects Contracted, 1998

\begin{tabular}{|lcrr|}
\hline Centre & $\begin{array}{c}\text { Projects } \\
\text { developed }\end{array}$ & \multicolumn{2}{c|}{ Projects } \\
commercialised
\end{tabular}

cused on consulting or service, as opposed to R\&D itself.

Table 9 shows that the provision of services was indeed the main concern of the centres in the technology subsystem during 1998. Most of them did not devote their S\&TP time into project development but rather into short-term services.

Any change in the priorities of these centres would inevitably lead to shifting objectives. Mexico needs to develop appropriate technology to assure a future for economic independence and eventually a higher standard of living for its population. If technology subsystems deviate their attention from S\&T projects to technology services, Mexico will continue indefinitely importing costly and sometimes obsolete technologies, seriously threatening its long pursued development goals.

Table 9. Commercialisation Drive, 1998

\begin{tabular}{|lrc|}
\hline Centre & $\begin{array}{c}\text { Clients/ } \\
\text { S\&TP }\end{array}$ & $\begin{array}{c}\text { Technology } \\
\text { Projects/S\&TP }\end{array}$ \\
CIQA & 3,38 & 0,14 \\
CIATEC & 24,09 & 6,36 \\
COMIMSA & 0,69 & 0,62 \\
CIATEJ & 8,57 & 0,88 \\
CIATEQ & 1,08 & 1,25 \\
CIDESI & 14,90 & 0,47 \\
CIDETEQ & 5 & 0,45 \\
& & \\
\hline
\end{tabular}

S\&TP: scientific and technical personnel. 


\section{The Triple Helix Model}

It is evident that in addition to the general Triple Helix Model (Leydesdorff and Etzkowitz, 1998; Etzkowitz and Leydesdorff, 1997), more specific Triple Helix configurations are being developed according to particular conditions in various countries (Etzkowitz et al., 1998; Fujigaki and Nagata, 1998; Jones-Evans and Klofsten, 1998; van Duinen, 1998). Latin American is no exception. Although governments since the early 1970's were seeking to build solid and fruitful links between university, industry and government, most of their efforts turned out to be disappointing. During the 1990's, the governmental part of the helix has been active in developing some collaboration between the three components, to cope with demands posed by a knowledge-based economy in Mexico (Casas and Luna, 1997).

Universities are quite conservative and change reluctantly at a slow pace. However, since the winds of modernity and globalisation impinge upon all sorts of institutions, they have also influenced higher education, where most of R\&D takes place. Public universities in Latin America have been subject to reductions in the subsidies provided by governments, which in turn have challenged their own survival. Hence they have been looking for additional sources of income. Budget cuts have encouraged the emergence of links with potential sponsors in the private sector, industry in particular. However, the relationship has not been as positive and intense as desired. On the one hand, most of the science and technology required by modern industry is either acquired from developed countries, or realised by their own R\&D labo- ratories. On the other hand, demands from local industry have generally involved minor technological advances.

As described in the previous section, the SEP-CONACYT technology subsystem has shown a different pattern of engagement. Even though only a couple of these centres have been involved with teaching at graduate levels and only three of them perform basic research, they all share as their primary objective the involvement in local and national industry problems, and the search for technology solutions. Furthermore, since federal policies began to stress social accountability, especially during the mid 1990's, the centres have been urged to seek economic self-sufficiency, i.e. to increase the share of its own resources with regard to their overall total expenditures. In order to do so in a more effective and efficient way, they realised they should enhance their level of activity in research, teaching, and consulting appropriate to the local and/or regional demands that existed. Since they do not have the human capital required to excel in these areas, they have started to make decisions regarding the establishment of strategic alliances with universities and other R\&D centres, in and out of the SEP-CONACYT system, which thus far have proven successful.

\section{Survival Strategies}

The pattern that these $R \& D$ centres have followed shows two different engagement models. Model A stresses the origin of some centres (specially CIQA and CIDETEQ) in close relationship with universities, as displayed in Figure 1, whereas Model "B" shows a much higher initial inclination to industrial services 
(all other centres), as shown in Figure 2. In the following two sections we will discuss some characteristics of both models and provide information from the technology subsystem to exemplify them.

\section{Centres Created in Close Relationship with Universities (Model A)}

This model stresses the need to establish closer ties with industry since budget cuts and current public policies threaten basic research. The Mexican government has called for stronger efforts to increase the share of self-generated budgets through very specific and demanding policies. All official efforts are thus being directed towards fostering participation of all economic sectors in financing S\&T as well as increasing interactions with industry.

A strategy frequently explored in order to diminish financial vulnerability of many $R \& D$ institutions complying with this model, relies on increasing the number of potential clients for their S\&T projects.

\section{Centres Created in Close Relationship with Industry (Model B)}

The enhancement of activity levels in centres complying with this model demand to strengthen their relationships with the academic part of the helix, i.e. with universities and other R\&D institutions. The commitment of Model B centres is to engage in more sophisticated applied projects that need the cooperation of highly specialised scientists. As pointed out earlier, since most centres do not count on personnel with these qualifications, they would have to hire faculty from universities, thus expanding the benefits of contracts with industry to higher education institutions, outside their regular action sphere.

In contrast, Model A centres have to seek R\&D problems in the outside world,

Figure 1. Model A for Centres in the Technology Subsystem.

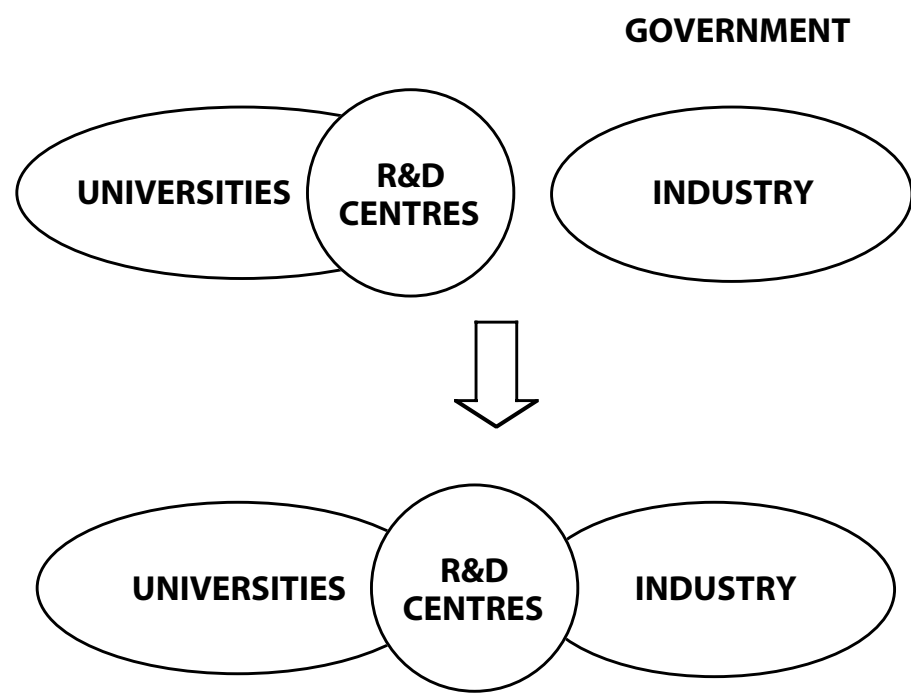


Figure 2. Model B for Centres in the Technology Subsystem.

\section{GOVERNMENT}

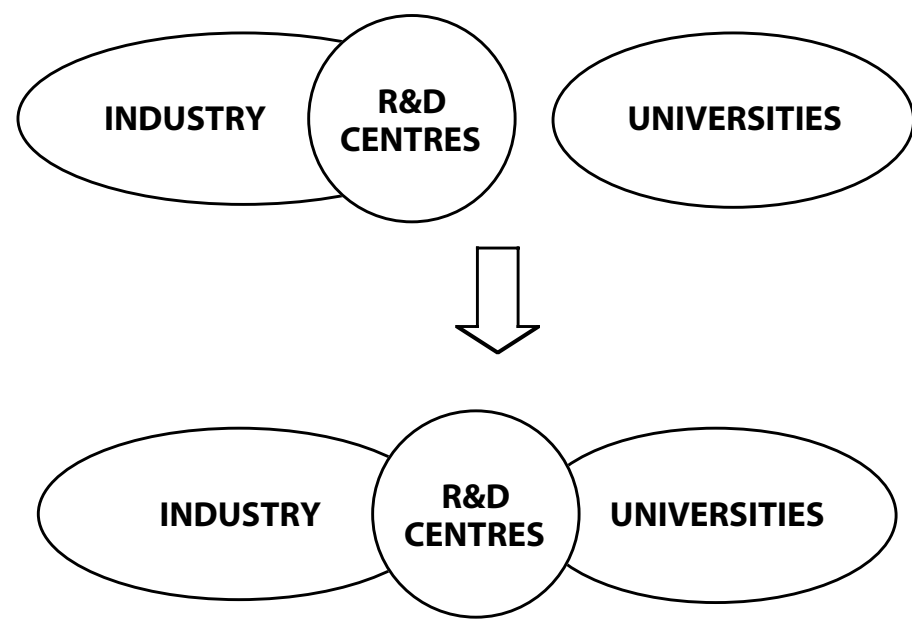

to prove their proficiency in the application of knowledge. These centres may find themselves in a more difficult situation than Model B centres, since the process of introduction and acceptance from industry is time consuming and has to overcome the traditional distrust from private sector towards public academic institutions.

\section{Conclusions}

We have shown a particular way of understanding the Triple Helix Model in a Latin American context. This, however, is not the only model observed in the area. The major challenge the technology subsystem is facing is its viability as an effective "connecting device" between the knowledge generated in other research centres and universities and its application in the "real" world. The centres in that subsystem will preserve the state support as long as they effectively link the parts involved, to the benefit of both industries and universities. Never- theless, in order to survive they must implement strategies that will strengthen self-sufficiency since the government's general trend is to reduce subsidies traditionally allocated to both higher education and S\&T.

According to the typology introduced, Model A centres will have to emphasise the relationship with industrial consumers of new technology. In contrast, Model B centres will have to approach academic institutions in order to identify knowledgeable individuals and research units that will help them enhance the scope of S\&T capabilities offered to their clients in industry. Although these centres are referred to as a "system", they are far from constituting a real system in which the parts are closely interconnected. Government authorities are making every effort to help them become more of a system, which will, in turn, make them more self-sustainable. A set of policies is being implemented to this end, in which the following points are emphasised: 
- An effective coordination among different participating actors (industries, firms, innovation centres, technology development institutions and universities).

- The creation of information networks to facilitate and increase interactions among all actors involved, while promoting the use of knowledge springing from that relationship.

- The training of human resources in areas such as technical specialisation and scientific research.

It is widely accepted that much of the research done in higher education institutions is going to add value to products in the market. The "connecting device," however, (i.e. the technology centres) has to develop and enhance their ability to understand the needs of industry and identify the individuals in academia who possess the necessary knowledge to help in the "translation" of academic knowledge into applied knowledge. This is indeed a way of understanding the Triple Helix Model, the successful implementation of which is yet to be seen.

\section{Notes}

1 The Scientific Research Subsystem includes nine science institutions, ten in the social sciences, and seven technology institutions belonging to the so-called Technology Subsystem. An additional centre, infotec, offers services on information technologies.

2 All information provided in this paper was taken from Annual Evaluation Reports (Informe de Autoevaluación) presented by the centres to CONACYT and to their respective Boards of Governance during their second 1999 meeting held in May 1999.

3 Unfortunately, the authors have not been able to find the reason of this shift from jewellery to food related processes. Ultimately, it may be due to the fact that the former did not find enough economic support in order to survive, while the latter proved to be more promising. This assumption corroborates our previous hypothesis on the likelihood of the random origin of most of these centres.

4 For a complete story on the foundation of these centres, see CONACT (1998).

5 "Contract income" is also referred to as "self-generated resources" as opposed to the budget provided by the federal government since these centres are all stateowned; i.e. highly subsidised. 


\section{References}

Anderson, F.

1998 "Where is Research Located in Canada? A Statistical Approach." Science and Public Policy 25, 6: 396-406.

Casas, R. \& Luna M.

1997 "Government, Academia and the Private Sector in Mexico: Towards a new Configuration." Science and Public Policy 24, 1: 7-14.

CONACYT

1998 "Historia de las Instituciones del Sistema SEP-CONACYT." (History of SEPCONACYT System's Institutions). México: CONACYT.

1999 "Informes de Autoevaluación de las Entidades SEP-CONACYT, 2a Sesión de Órganos de Gombierno, Mayo 1999." (self-evaluation Reports of the SEPCONACYT's Centres, 2nd session of the Board of Governance, May 1999). México: CONACYT.

Etzkowitz, H. \& Leydesdorff L. (eds.)

1997 Universities and the Global Knowledge Economy: A Triple Helix of UniversityIndustry-Government Relations. Cassel Academic: London.

Etzkowitz, H., Mello, J.M.C. \& Cantisano

Terra, B.R.

1998 "When Path Dependencies Collide: The Evolution of Innovation Policy in the State of Rio de Janeiro, Brazil.” Science and Public Policy, 26, 6: 365-371.

Fujigaki, Y. \& Nagata A.

1998 "Concept Evolution." Science and Public Policy 26, 6: 387-395.

Jiménez, J., Campos, M., \& Escalante, J.

1991 "Distribution of Scientific Tasks Between Centre and Periphery in Mexico." Social Science Information 30, 3: 471482.
Jiménez, J., Campos, M.A., Domìnguez, J., \& Romano, L.

1986 "Centre-Periphery Analysis of Research and Development Resource Allocation: Preliminary Results of ICSOPRU in Mexico." Comunicaciones Técnicas, Iimas, Unam, serie naranja: investigaciones 436:1-62.

Jones-Evans, D. \& Klofsten, M.

1998 "Role of the University in the Technology Transfer Process: A European View." Science and Public Policy, 25,6: 373-380.

Leydesdorff, L. \& Etzkowitz, H.

1998 "Triple Helix of Innovation: Introduction." Science and Public Policy 25, 6: 358-364.

van Duinen, R.J.

1998 "European Research Councils and the Triple Helix." Science and Public Policy 25, 6: 381-386.

Judith Zubieta and

Jaime Jiménez

Social Research Institute and Institute of Applied Mathematics and Systems, National Autonomous University of Mexico, UNAM

Mexico City, Mexico 